Quim. Nova, Vol. 34, No. 1, 156-159, 2011

\title{
VALIDAÇÃO DE MÉTODO PARA DETERMINAÇÃO DE ÁCIDOS ORGÂNICOS VOLÁTEIS EM EFLUENTES DE REATORES ANAERÓBIOS EMPREGANDO CROMATOGRAFIA LÍQUIDA
}

\author{
Maristela Barnes Rodrigues Cerqueira, Adriana Neves Dias, Sergiane Souza Caldas, Fabrício Butierres Santana, Marcelo \\ Gonçalves Montes D'Oca e Ednei Gilberto Primel* \\ Escola de Química e Alimentos, Universidade Federal do Rio Grande, Campus Carreiros, Av. Itália km 8, s/n, $96201-900$ Rio \\ Grande - RS, Brasil
}

Recebido em 24/3/10; aceito em 16/6/10; publicado na web em 9/11/10

\begin{abstract}
METHOD VALIDATION FOR THE DETERMINATION OF VOLATILE FATTY ACIDS IN WASTEWATERS FROM ANAEROBIC REACTORS EMPLOYING LIQUID CHROMATOGRAPHY. This work deals with the method validation for the determination of acetic, propionic and butyric acids (VFAs) in wastewaters from anaerobic reactors by HPLC-DAD. Separation was performed using a C18 column and the mobile phase composition were water $\mathrm{pH} 3.0$ and methanol 90:10 (v/v). The detection and quantification was carried out at $220 \mathrm{~nm}$. The method shows good linearity $\left(\mathrm{r}^{2}>0.996\right)$, with adequate accuracy (89-102\%) and relative standard deviations lower than $18 \%$. The matrix effect was considered low (-4.1, -3.9 and 1.4\%). The developed method is fast, simple and cheap; and it was applied in wastewater samples from anaerobic reactor.
\end{abstract}

Keywords: VFAs; matrix effect; HPLC-DAD.

\section{INTRODUÇÃO}

Atualmente, o Brasil é o principal protagonista mundial na produção e na utilização de combustíveis renováveis; a produção de hidrogênio através de processos de digestão anaeróbia é uma alternativa para o futuro. O país já tomou a decisão estratégica em favor da economia do hidrogênio, embora o Programa Nacional de Produção e Uso do Hidrogênio ainda esteja em fase de elaboração, sob coordenação do Ministério das Minas e Energia. Desde 2005, entretanto, o Roteiro para a Estruturação da Economia do Hidrogênio no Brasil aponta as principais demandas de pesquisa e desenvolvimento científico e tecnológico para que o uso comercial do hidrogênio, a partir de diversas rotas, possa ser alcançado, por exemplo, da gaseificação da biomassa e processos alternativos (marco global IV, 2025). ${ }^{1}$

Na digestão anaeróbia de efluentes, os três grupos de microorganismos responsáveis pela decomposição da matéria orgânica em metano, dióxido de carbono e pequenas concentrações de gás hidrogênio são as bactérias fermentativas (ou acidogênicas), as sintróficas (ou acetogênicas) e as metanogênicas. As bactérias acidogênicas são as primeiras a atuar no processo de digestão anaeróbia. Elas fermentam açúcares, aminoácidos e ácidos graxos resultantes da hidrólise da matéria orgânica complexa e produzem ácidos orgânicos voláteis (AOVs, principalmente ácidos acético, propiônico e butírico), alcoóis (etanol), cetonas (acetona), dióxido de carbono e hidrogênio. ${ }^{2}$

A etapa fermentativa da digestão anaeróbia é o processo chave na produção de hidrogênio. Através dessa etapa, os micro-organismos acidogênicos decompõem a matéria orgânica, por exemplo, os carboidratos, em $\mathrm{H}_{2(\mathrm{~g})}, \mathrm{CO}_{2(\mathrm{~g})}$ e AOVs. Deste modo, a etapa fermentativa possibilita tanto a transformação da matéria orgânica em compostos facilmente degradáveis quanto a produção de hidrogênio, obtendose, consequentemente, energia limpa a partir de resíduos orgânicos. ${ }^{3}$

Ácidos carboxílicos com baixa massa molecular $\left(\mathrm{C}_{2}-\mathrm{C}_{5}\right)$ são importantes intermediários e metabólitos no processo de digestão anaeróbia e são conhecidos como ácidos orgânicos voláteis (AOVs), correspondendo aos ácidos acético, propiônico, iso- e $n$-butírico e iso

\footnotetext{
*e-mail: eprimelfurg@gmail.com
}

e $n$-valérico, ${ }^{4}$ sendo os ácidos acético, propiônico e butírico os mais importantes quantitativamente nesse processo. ${ }^{5}$

Como a presença de $\mathrm{AOV}$ s, geralmente, é um indicativo de atividade bacteriana, ${ }^{4}$ a determinação das concentrações de AOVs tem sido utilizada como um indicador útil no monitoramento da produção de hidrogênio. Os AOVs podem ser estimulantes, inibidores ou mesmo tóxicos para as bactérias fermentativas. Níveis baixos de concentração de AOVs podem não ter efeito ou ter um efeito estimulante sobre a produção de hidrogênio. No entanto, em níveis elevados de concentração, os AOVs podem levar a uma severa inibição sobre a geração de hidrogênio., ${ }^{6,7}$

Muitos tratamentos de resíduos e aplicações ambientais necessitam da determinação de AOVs, na faixa de concentração de 1 a 5000 $\mathrm{mg} \mathrm{L}^{-1}$, e envolvem uma variedade de matrizes. ${ }^{4}$

Cromatografia gasosa $(\mathrm{CG})^{4,8}$ e cromatografia líquida $(\mathrm{CL})^{9-12}$ são as técnicas empregadas pelos métodos analíticos para a determinação de AOVs em águas residuais. Dentre os trabalhos citados que utilizaram CL, apenas um empregou fase reversa e detecção no ultravioleta (UV), ${ }^{12}$ os demais utilizaram colunas de troca iônica com detecção no UV e por índice de refração (IR). ${ }^{9-11}$

$\mathrm{O}$ preparo de amostra nos métodos que utilizaram CG foi feito por headspace, ${ }^{4,8}$ enquanto nos métodos empregando CL, em apenas um foi feita a diluição das amostras. ${ }^{12}$ Nos demais métodos, o preparo de amostra não foi descrito. ${ }^{9-11}$ Já o estudo do efeito matriz do lodo anaeróbio foi realizado em apenas um trabalho. ${ }^{11}$

Ao considerar a importância dos níveis dos AOVs no processo de produção de hidrogênio, o objetivo deste estudo foi desenvolver e validar um método analítico simples, rápido e eficiente para monitorar as concentrações dos principais AOVs (acético, propiônico e butírico) em efluentes de reatores anaeróbios, empregando CL com fase reversa e detecção por arranjo de diodos (DAD) enfocando o efeito matriz.

\section{PARTE EXPERIMENTAL}

\section{Reagentes}

Os padrões analíticos dos ácidos butírico (pureza $\geq 99 \%$ ) e propiônico (pureza > 99,5\%) foram obtidos da Sigma-Aldrich (São Paulo, 
Brasil). O ácido acético (pureza 96\%) e o ácido fosfórico (85\%), ambos grau analítico, foram adquiridos da Merck (Darmstadt, Alemanha). Metanol e acetonitrila, grau HPLC, foram fornecidos pela J.T. Baker (Mallinckrodt, Phillisburg, NJ, USA), e a água foi purificada em sistema Direct-Q UV3 ${ }^{\circledR}$ (resistividade 18,2 M $\Omega \mathrm{cm}$, Millipore, USA).

\section{Instrumentação}

A separação foi realizada em sistema de cromatografia líquida Waters (Milford, MA, USA) composto por bomba 600, detector PDA 2996, válvula injetora Rheodyne, com alça de $20 \mu \mathrm{L}$ e sistema de aquisição de dados Empower $2^{\circledR}$ software.

Para a otimização do método, foram testadas duas colunas com fase estacionária compostas por C18, Waters Spherisorb ODS2 $80 \AA$ ( 150 x 4,6 mm, $5 \mu \mathrm{m}$ - Milford, MA, USA) e Phenomenex Synergi Fusion RP $80 \AA$ ( 250 x 4,6 mm, $4 \mu \mathrm{m}$-Torrance, CA, USA).

A identificação dos AOVs nas amostras foi realizada com base nos seus tempos de retenção e pela comparação entre os espectros, na região do ultravioleta, dos compostos nas soluções padrão e dos picos detectados nas amostras. Testes para avaliar a pureza dos picos também foram realizados. Para a quantificação foi selecionado o comprimento de onda de $220 \mathrm{~nm}$.

\section{Preparo das soluções e fase móvel}

Foram preparadas soluções estoque individuais dos ácidos em água purificada na concentração de $1000,0 \mathrm{mg} \mathrm{L}^{-1}$. As soluções trabalho e intermediárias da mistura dos AOVs foram obtidas a partir da diluição da solução estoque por meio de diluições sucessivas. Estas soluções foram utilizadas na otimização e validação do método.

Na otimização da separação foram testadas diferentes fases móveis compostas por diferentes proporções de metanol, acetonitrila e água purificada com pH 3,0 acidificada com ácido fosfórico (1:1) (v/v).

As fases móveis foram filtradas em membrana de nylon $(0,45$ $\mu \mathrm{m})$ da Millipore ${ }^{\circledR}$ (SP, Brasil) e desgaseificadas por $30 \mathrm{~min}$ em um banho de ultrassom.

\section{Amostras}

As amostras utilizadas para a validação do método foram provenientes de um reator anaeróbio de fluxo ascendente com manta de lodo, utilizado para o tratamento de águas residuárias industriais, operado com carga orgânica de 2,5 $\mathrm{kg} \mathrm{L}^{-1}$ de DQO (demanda química de oxigênio), em temperatura controlada a $35^{\circ} \mathrm{C}$. As amostras foram coletadas e analisadas em no máximo 24 h após a coleta. Devido à alta concentração dos compostos de interesse nas amostras, as mesmas foram diluídas 10 vezes tanto para a validação do método como para a aplicação do mesmo.

As amostras foram filtradas em filtro Millex ${ }^{\circledR} \mathrm{HV}$ PVDF $(0,45$ $\mu \mathrm{m})$ da Millipore ${ }^{\circledR}$ (Cork, Ireland) e, em seguida, foram diluídas dez vezes em água purificada.

\section{Validação do método}

O método foi validado de acordo com parâmetros sugeridos pela ANVISA e pelo INMETRO..$^{13,14}$ Os parâmetros considerados na validação foram curva analítica e linearidade, limites de detecção (LD) e de quantificação (LQ), exatidão (adição padrão e recuperação) e precisão (repetibilidade e precisão intermediária). Foi avaliado também o efeito matriz.

$\mathrm{O}$ efeito matriz tem sido amplamente estudado, por ser considerado como fonte de erro quantitativo devido à interferência de componentes da matriz. ${ }^{15}$
Limites de detecção $(L D)$ e de quantificação $(L Q)$

Neste estudo, LD e LQ foram determinados considerando-se como as concentrações que produziram um sinal 3 e 10 vezes, respectivamente, o ruído da linha de base..$^{13}$

\section{Curva analítica e linearidade}

Para construir a curva analítica foram preparadas soluções analíticas nas concentrações de 7,5; 15,0; 30,0; 60,0; 120,0; 150,0 e 300,0 mg L-1. A curva analítica $(\mathrm{y}=\mathrm{ax}+\mathrm{b})$ foi construída do limite de quantificação de cada composto até a concentração de $300,0 \mathrm{mg} \mathrm{L}^{-1}$, resultando em sete níveis de concentração para os ácidos acético e propiônico e em seis níveis de concentração para o ácido butírico, sendo realizadas injeções em triplicatas para cada nível de concentração. Foram consideradas com boa linearidade curvas com valores de $\mathrm{r}^{2}>0,99 .{ }^{16}$

\section{Efeito matriz}

A avaliação do efeito matriz foi feita com base na comparação das inclinações das curvas analíticas dos ácidos no solvente e na matriz, conforme trabalhos prévios. ${ }^{15,17-19}$

Para isso foram preparadas soluções em sete níveis de concentração no solvente e na matriz para os ácidos acético e propiônico e em seis níveis para o ácido butírico, sendo realizadas injeções em triplicata para cada nível de concentração.

O cálculo para a avaliação do efeito matriz foi feito utilizando a Equação 1: ${ }^{15}$

$$
\mathrm{C} \%=100 \times\left(1-\frac{\mathrm{Sm}}{\mathrm{Ss}}\right)
$$

onde: $\mathrm{S}_{\mathrm{m}}=$ inclinação da curva obtida pela injeção das soluções analíticas de cada $\mathrm{AOV}$, preparados na matriz; $\mathrm{S}_{\mathrm{s}}=$ inclinação da curva obtida pela injeção das soluções analíticas de cada AOV, preparados no solvente.

\section{Exatidão}

Para avaliar a exatidão foram adicionadas quantidades conhecidas dos ácidos acético, propiônico e butírico nas amostras de efluente, dez vezes diluídas. O estudo foi realizado em dois níveis, 7,5 $\mathrm{mg} \mathrm{L}^{-1}$ para os ácidos acético e propiônico, $15,0 \mathrm{mg} \mathrm{L}^{-1}$ para o ácido butírico e 60,0 $\mathrm{mg} \mathrm{L}^{-1}$ para os três compostos. As amostras sem adição de padrão e cada uma das amostras com o padrão adicionado foram injetadas no sistema cromatográfico em triplicata $(n=9)$.

A exatidão foi avaliada pelo método de adição padrão para os ácidos acético e butírico. Este método é utilizado quando é difícil ou impossível preparar um branco da matriz isenta da substância de interesse. ${ }^{16}$ Os resultados foram expressos em termos de quantidade medida da substância em relação à quantidade adicionada na matriz, conforme a Equação 2:

$$
\text { Exatidão por Adição Padrão (\%) = } \frac{\text { quantidade medida }- \text { branco }}{\text { quantidade adicionada }} \times 100
$$

Para o ácido propiônico, a exatidão do método foi avaliada em termos de recuperação, já que o composto não esteve presente na amostra. Os resultados foram expressos pela relação entre a concentração média determinada experimentalmente e a concentração teórica correspondente, conforme a Equação 3: ${ }^{16}$

$$
\mathrm{R}(\%)=\frac{\text { concentração medida }}{\text { concentração teórica }} \times 100
$$

\section{Precisão}

No estudo da precisão do método foram avaliadas a repetibilidade e a precisão intermediária. Para a repetibilidade, foram preparadas 9 
amostras, injetadas em triplicata no mesmo dia, pelo mesmo analista e nas mesmas condições cromatográficas. Para a precisão intermediária as amostras foram preparadas da mesma maneira e injetadas em dias diferentes. As respostas foram expressas em termos de coeficiente de variação percentual $(\mathrm{CV} \%)$.

\section{RESULTADOS E DISCUSSÃO}

\section{Parâmetros cromatográficos}

As duas colunas testadas apresentaram bons resultados. No entanto, foi escolhida a coluna Waters Spherisorb ODS2 80 $(150$ x 4,6 mm, 5 um - Milford, MA, USA), pelo fato de apresentar um tempo menor de análise cromatográfica.

Na otimização da separação dos compostos, a acidificação da água purificada a pH 3,0 utilizada na fase móvel foi uma condição previamente determinada e mantida constante, devido ao caráter ácido dos compostos. ${ }^{12} \mathrm{~A}$ adição de ácido à fase móvel causa a supressão da ionização de grupos funcionais ácidos e promove uma interação maior dos compostos com a fase estacionária.

A fase móvel consistiu numa mistura isocrática entre metanol/água (10:90). Apesar de se ter obtido um bom resultado utilizando acetonitrila, optou-se pelo uso do metanol, uma vez que o custo da acetonitrila é elevado. O modo de eluição isocrático com vazão da fase móvel de 1,0 mL min ${ }^{-1}$ resultou em um tempo total de análise cromatográfica de 10 min. Na Figura 1 é apresentado um cromatograma da condição otimizada com os respectivos espectros de absorção de cada composto, para o branco da amostra, para a mistura dos padrões a $60 \mathrm{mg} \mathrm{L}^{-1} \mathrm{e}$ para a amostra com adição da mistura dos padrões a $60 \mathrm{mg} \mathrm{L}^{-1}$.

A seleção do comprimento de onda para a quantificação dos três compostos foi realizada após a varredura espectral da região do ultravioleta-visível (190-800 nm), sendo que o comprimento de onda que apresentou uma resposta satisfatória foi de $220 \mathrm{~nm}$.

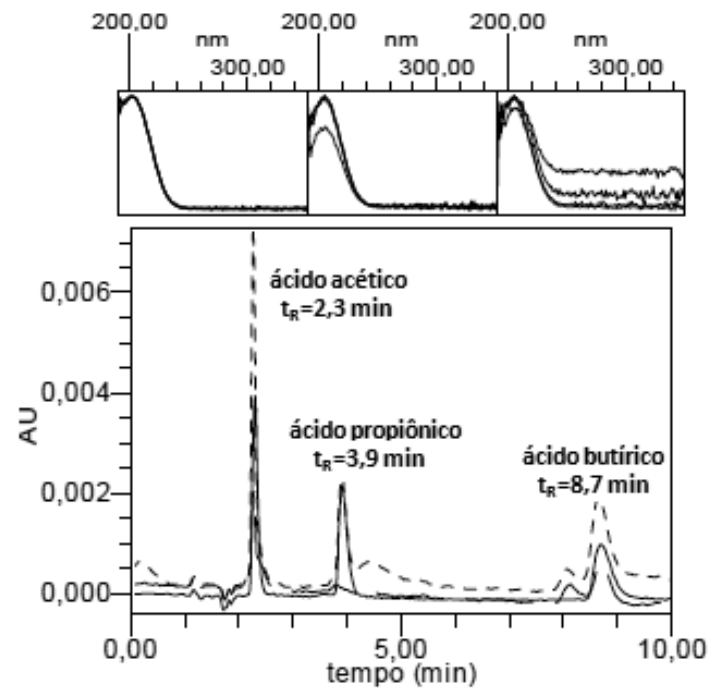

Figura 1. Cromatogramas do branco da amostra (tracejado), mistura dos padrões $60 \mathrm{mg} \mathrm{L}^{-1}$ (linha) e amostra com adição da mistura dos padrões 60 $m g L^{-1}$ (pontilhado) e os espectros de absorção de cada composto

\section{Validação}

\section{$L D$ e $L Q$}

Os LD obtidos para os ácidos foram de $2,25 \mathrm{mg} \mathrm{L}^{-1}$ para os ácidos acético e propiônico e de 4,5 $\mathrm{mg} \mathrm{L}^{-1}$ para o ácido butírico e os LQ para os ácidos acético e propiônico de 7,5 e de $15,0 \mathrm{mg} \mathrm{L}^{-1}$ para o ácido butírico.
Ao comparar esses valores com os encontrados na literatura, ${ }^{10-12}$ o método apresentou menores valores de LQ.

\section{Curva analítica e linearidade}

A faixa linear de trabalho para determinação de AOVs apresenta bastante variação. No método que empregou CL com coluna de troca iônica e com detecção no UV e por IR, as faixas lineares foram de 60 a $600 \mathrm{mg} \mathrm{L}^{-1}$ para o ácido acético, 74 a $740 \mathrm{mg} \mathrm{L}^{-1}$ para o ácido propiônico e 88 a $880 \mathrm{mg} \mathrm{L}^{-1}$ para o ácido butírico; ${ }^{11}$ já no método que utilizou CL com fase reversa e detecção no UV, as faixas lineares foram de 20 a $90 \mathrm{mg} \mathrm{L}^{-1}$ para o ácido acético e de 35 a $280 \mathrm{mg} \mathrm{L}^{-1}$ para os ácidos propiônico e butírico. ${ }^{12}$

Neste estudo as faixas lineares foram de 7,5 a $300 \mathrm{mg} \mathrm{L}^{-1}$ para os ácidos acético e propiônico e de 15,0 a 300,0 $\mathrm{mg} \mathrm{L}^{-1}$ para o ácido butírico. O método proposto apresenta a vantagem de quantificar os ácidos em baixas concentrações; por outro lado, pode ser também aplicado a amostras com altas concentrações dos ácidos através da diluição das mesmas.

As curvas analíticas nas faixas lineares, anteriormente mencionadas, apresentaram excelentes valores para os coeficientes de correlação $\left(\mathrm{r}^{2}\right)$ para os três compostos, iguais a 0,999, Tabela 1.

Tabela 1. Valores de $\mathrm{r}^{2}$, curva analítica e faixa linear para os ácidos acético, propiônico e butírico no solvente

\begin{tabular}{lccc}
\hline Compostos & $\mathrm{r}^{2}$ & Curva analítica & $\begin{array}{c}\text { Faixa linear } \\
\left(\mathrm{mg} \mathrm{L}^{-1}\right)\end{array}$ \\
\hline Ácido acético & 0,999 & $\mathrm{y}=428,65 \mathrm{x}-540,88$ & $7,5-300,0$ \\
Ácido propiônico & 0,999 & $\mathrm{y}=370,17 \mathrm{x}-520,37$ & $7,5-300,0$ \\
Ácido butírico & 0,999 & $\mathrm{y}=378,98 \mathrm{x}-803,55$ & $15-300,0$ \\
\hline
\end{tabular}

As curvas analíticas realizadas com a interferência da matriz também apresentaram excelente linearidade nas mesmas faixas de concentrações com coeficiente de correlação $\left(r^{2}\right)$ variando de 0,996 a 0,999 para os três compostos, conforme a Tabela 2 .

Tabela 2. Valores de $\mathrm{r}^{2}$, curva analítica e faixa linear para os ácidos acético, propiônico e butírico na matriz

\begin{tabular}{lccc}
\hline Compostos & $\mathrm{r}^{2}$ & Curva analítica & $\begin{array}{c}\text { Faixa linear } \\
\left(\mathrm{mg} \mathrm{L}^{-1}\right)\end{array}$ \\
\hline Ácido acético & 0,999 & $\mathrm{y}=422,66 \mathrm{x}-273,33$ & $7,5-300,0$ \\
Ácido propiônico & 0,999 & $\mathrm{y}=384,75 \mathrm{x}+1166,8$ & $7,5-300,0$ \\
Ácido butírico & 0,996 & $\mathrm{y}=394,52 \mathrm{x}-2557,6$ & $15-300,0$ \\
\hline
\end{tabular}

Avaliação do efeito matriz.

O efeito matriz foi de 1,$4 ;-3,9$ e -4,1\% para os ácidos acético, propiônico e butírico, respectivamente. O efeito matriz é considerado baixo para intervalos entre $-20 \%<\mathrm{C} \%<20 \%$, médio para os intervalos $-50 \%<\mathrm{C} \%<-20 \%$ ou $20 \%>\mathrm{C} \%>50 \%$ e elevado para os intervalos $\mathrm{C} \%<-50 \%$ ou $\mathrm{C} \%>50 \% .^{15}$ Portanto, pode-se verificar que o efeito matriz na quantificação dos AOVs é baixo.

\section{Exatidão}

Os valores de exatidão variaram entre 89 a $102 \%$ (Tabela 3), estando de acordo com os valores aceitos pela literatura para matrizes complexas que aceitam valores entre $80-120 \% .{ }^{16}$

\section{Precisão}

Os coeficientes de variação percentual (CV\%) apresentaram valores menores que $18 \%$ (Tabela 3 ) indicando que o método é preciso, 
Tabela 3. Resultados de exatidão do método para os ácidos acético, propiônico e butírico e de precisão em termos de repetibilidade $\left(\mathrm{CV}_{r}\right)$ e precisão intermediária $\left(\mathrm{CV}_{p i}\right)(\mathrm{n}=9)$

\begin{tabular}{|c|c|c|c|c|c|c|c|c|}
\hline Compostos & $\begin{array}{l}\text { Adicionado } \\
\left(\mathrm{mg} \mathrm{L}^{-1}\right)\end{array}$ & $\begin{array}{l}\text { Medido } \\
\left(\mathrm{mg} \mathrm{L}^{-1}\right)\end{array}$ & $\begin{array}{c}\text { Exatidão } \\
(\%)\end{array}$ & $\begin{array}{l}\mathrm{CV}_{\mathrm{r}} \\
(\%)\end{array}$ & $\begin{array}{l}\text { Adicionado } \\
\left(\mathrm{mg} \mathrm{L}^{-1}\right)\end{array}$ & $\begin{array}{l}\text { Medido } \\
\left(\mathrm{mg} \mathrm{L}^{-1}\right)\end{array}$ & $\begin{array}{l}\text { Exatidão } \\
(\%)\end{array}$ & $\begin{array}{l}\mathrm{CV}_{\mathrm{pi}} \\
(\%)\end{array}$ \\
\hline \multirow[t]{2}{*}{ Ácido acético } & 7,5 & 7,5 & 100 & 9,5 & 60,0 & 60,1 & 100 & 7,2 \\
\hline & 7,5 & 7,3 & 98 & 6,4 & 60,0 & 59,7 & 99,6 & 2,3 \\
\hline \multirow[t]{2}{*}{ Ácido propiônico } & 7,5 & 7,3 & 98 & 17,6 & 60,0 & 54,1 & 90,1 & 6,2 \\
\hline & 7,5 & 7,6 & 101,7 & 10,9 & 60,0 & 61,2 & 102 & 7,4 \\
\hline \multirow{2}{*}{$\begin{array}{l}\text { Ácido } \\
\text { butírico }\end{array}$} & 15,0 & 14,9 & 99,2 & 7,1 & 60,0 & 59,9 & 99,8 & 8,9 \\
\hline & 15,0 & 13,4 & 89,6 & 9,7 & 60,0 & 57,7 & 96,2 & 3,6 \\
\hline
\end{tabular}

já que para análises de traços ou impurezas, são aceitos CV\% de até $20 \%$, dependendo da complexidade da amostra. ${ }^{16}$

\section{Aplicabilidade do método}

O método foi aplicado em amostras de efluente provenientes da cabeça e da cauda de um reator anaeróbio e os valores de concentrações encontrados estão descritos na Tabela 4. Na Tabela 5 encontram-se os valores reais de concentrações provenientes desse reator anaeróbio de fluxo ascendente com manta de lodo, utilizado para o tratamento de águas residuárias industriais.

Tabela 4. Valores de concentrações para as amostras de efluentes de reatores anaeróbios

\begin{tabular}{lcccc}
\hline Composto & \multicolumn{2}{c}{ Cabeça $\left(\mathrm{mg} \mathrm{L}^{-1}\right)$} & \multicolumn{2}{c}{ Cauda $\left(\mathrm{mg} \mathrm{L}^{-1}\right)$} \\
\hline \multirow{2}{*}{ Ácido acético } & Matriz & $(\mathrm{CV} \%)$ & Matriz & $(\mathrm{CV} \%)$ \\
Ácido propiônico & 25,0 & 8,8 & 40,1 & 7,9 \\
Ácido butírico & $<\mathrm{LQ}$ & - & 24,0 & 3,5 \\
\hline
\end{tabular}

onde, $<\mathrm{LQ}=$ menor que o Limite de Quantificação

Tabela 5. Valores de concentrações reais para as amostras de efluentes de reatores anaeróbios

\begin{tabular}{lcccc}
\hline Composto & \multicolumn{2}{c}{ Cabeça $\left(\mathrm{mg} \mathrm{L}^{-1}\right)$} & \multicolumn{2}{c}{ Cauda $\left(\mathrm{mg} \mathrm{L}^{-1}\right)$} \\
\hline \multirow{2}{*}{ Ácido acético } & Matriz & $(\mathrm{CV} \%)$ & Matriz & $(\mathrm{CV} \%)$ \\
Ácido propiônico & 250 & 8,8 & 401 & 7,9 \\
Ácido butírico & $<\mathrm{LQ}$ & - & 240 & 3,5 \\
\hline
\end{tabular}

onde, $<\mathrm{LQ}=$ menor que o Limite de Quantificação

\section{CONCLUSÕES}

O método proposto apresenta algumas vantagens em relação aos métodos citados. É um método sensível, rápido, não utiliza forno na coluna como os outros métodos e faz uso de metanol como fase móvel, uma vez que os demais utilizam acetonitrila que é um solvente com custo mais elevado.

A avaliação do efeito matriz mostra que o método é confiável, eficiente e apresenta ótimas linearidade, precisão e exatidão, per- mitindo o seu uso como alternativa para determinação de AOVs em efluentes de reatores anaeróbios.

\section{REFERÊNCIAS}

1. http://www.mct.gov.br/index.php/content/view/73412.html, acessada em Outubro 2010.

2. Aquino, S. F.; Chernicharo, C. A. L.; Eng. sanit. ambient. 2005, 10, 152.

3. Fernandes, B. S.; Tese de Doutorado, Universidade de São Paulo, Brasil, 2008.

4. Cruwys, J. A.; Dinsdale, R. M.; Hawkes, F. R.; Hawkes, D. L.; J. Chromatogr., A 2002, 945, 195.

5. Tangermann, A.; Nagengast, F. M.; Anal. Biochem. 1996, 236, 1.

6. Dong, L.; Zhenhong, Y.; Yongming, S.; Xiaoying, K.; Yu, Z.; Int. J. Hydrogen Energy 2009, 34, 812.

7. Zheng, X. J.; Yu, H. Q.; J. Environ. Management 2005, 74, 65.

8. Ábalos, M.; Bayona, J. M.; Pawliszyn, J.; J. Chromatogr., A 2000, 873, 107.

9. Ribas, M. M. F.; Moraes, E. M.; Foresti, E.; Eng. sanit. ambient. 2007, 12,240 .

10. Chiapetta, S. C.; Hirasawa, J. S.; Lazaro, C. Z.; Livro de Resumos COLACRO XII \& SIMCRO, Florianópolis, Brasil, 2008.

11. Ferreira-Leitão, V. S.; Vasconcelos de Sá, L. R.; Livro de Resumos COLACRO XII \& SIMCRO, Florianópolis, Brasil, 2008.

12. Destandau, E.; Vial, J.; Hennion, M. C.; Bonnet, D.; Lancelin, P.; J. Chromatogr., A. 2005, 1088, 49.

13. Agência Nacional de Vigilância Sanitária (ANVISA); Resolução (RE) no 889, de 29/05/2003: Guia para validação de métodos analíticos e bioanalíticos, Ministério da Saúde: Brasil 2003.

14. Instituto Nacional de Metrologia, Normalização e Qualidade Industrial (INMETRO); Orientações sobre Validação de Métodos de Ensaios Químicos, DOQ-CGCRE-008, 2003.

15. Economou, A.; Botitsi, H.; Antoniou, S.; Tsipi, D.; J. Chromatogr, A $\mathbf{2 0 0 9}, 1216,5856$

16. Ribani, M.; Bottoli, C. B. G.; Collins, C. H.; Jardim, I. C. S. F.; Melo, L. F. C.; Quim. Nova 2004, 27, 771.

17. Fernández, L. V.; Hernáez, A. S.; Asensio, J. S.; Zurbano, P. F.; Ramírez, M. S.; Jubera, B. P.; Alonso, M. L.; Fernández, S. I. E; Soria, M. T. M.; J. Sci. Food Agric. 2008, 88, 1943.

18. Villagrasa, M.; Guillamón, M.; Eljarrat, E.; Barceló, D.; J. Chromatogr., A 2007, 1157, 108.

19. Stipicevic, S.; Fingler, S.; Kralj, L. Z.; Drevenkar, V.; J. Sep. Sci. 2003, 26, 1237. 